\title{
RUNOFF GENERATION UNDER DIFFERENT LAND USES AT HORTON PLAINS
}

\author{
J.M. Nimal Chandrasiri and E.R.N. Gunawardana \\ Department of Agricultural Engineering, University of Peradeniya.
}

\begin{abstract}
Surface runoff occurs when the rate of precipitation exceeds the rate of infiltration. Under different land-use types the soil properties that can affect the wav in which runoff takes place may vary significantly. At Horton Plains, there are two distinct vegetation types, cloud forest and grassland (natural as well as re-established after cultivation about twenty years ago), which might be supposed to affect runoff. This study was conducted to explain the runoff generation process at these sites by determining soil texture, organic matter content, bulk density, infiltration and hydraulic conductivity under each land use. The bulk density of the top $100 \mathrm{~cm}$ of the soil is exceptionally low in all land-use types, because of the high organic matter content. This low density increases the infiltration rate. Comparison of rainfall intensities with infiltration rates indicated that in forest and natural grassland, for all the rainfall events of the first six months of 1996, rainwater would have entered the soil without generating surface runoff, and this would have been true also of the formerly cultivated grassland for most of the events. However, the hydraulic conductivity values at depths below $150 \mathrm{~cm}$ are low compared with the infiltration rates, indicating that, water must preferentially move laterally to the streams through the upper part of the soil profile. Since the soil conditions are similar under all the land uses, it appears that at Horton Plains land use has only a marginal effect on the runoff process, compared with soil and climate.
\end{abstract}

\section{Introduction}

Runoff is the portion of precipitation making its way towards lower elevations as surface or sub-surface flow. The term "nunoff' is also often used loosely to mean surface flow (Glenn et al., 1981). Its amount is determined by climatic factors such as rainfall, soil factors, and landuse pattern. The rainfall factors that deternine runoff generation are intensity, duration and amount. The soil characteristics that affect infiltration, and that therefore influence the runoff rates, include soil texture and structure, organic matter content, and bulk density.

Vegetation cover or the land-use pattern affects runoff directly or indirectly: 
- Rainfall is intercepted and evaporated to the atmosphere by the vegetation, so that net rainfall reaching the ground is less than total rainfall.

- The soil physical properties may be altered; in particular, large amounts of biomass may increase the soil organic matter, which in turn will lead to increased infiltration.

- Vegetational cover prevents surface sealing of the soil and so increases the infiltration rate and reduces surface nunoff.

The nunoff generation process in the upland watersheds of major rivers in Sri Lanka is important in many respects. Total runoff is important, since $85 \%$ of the country's energy requirements are generated from hydropower. Continuous water flow in the streans is crucial for irrigated agriculture within the catchment, and also for domestic water supplies, since most of the people depend on agriculture and since they are not provided with piped water.

Hardly any work has been done to study the effect of land-use conversions in Sri Lanka on the water supply. It is particularly important to understand the hydrological processes operating under the different land-use types in the uplands, in order to assess the effect of conversions on the hydrological regime. Although Horton Plains has a high rainfall, as well as cloud deposition, there is hardly any surface nunoff visible even after heavy rainfall events. To elucidate the mechanisms at work, it was decided to study the primary factors that determine the nunoff generation process under different land-use patterns here. The results may also help us to understand the effect of land-use conversions elsewhere in the uplands.

\section{Objectives}

This study was conducted as part of UP-OFI Link Project. Its specific objectives were:

- To measure the infiltration rate of forest, natural grassland and formerly cultivated grassland at Horton Plains.

- To determine the soil texture. bulk density, organic-matter content, and hydraulic conductivity of soils under the above land-uses.

\section{Study site and method}

\section{Study site}

This study was conducted at Horton Plains $\left(2100-2300 \mathrm{~m} ; 6^{\circ} 47-50^{\prime} \mathrm{N}, 80^{\circ} 51^{\prime} \mathrm{E}\right)$ in the upcountry wet zone of the central highlands of Sri Lanka. The Horton Plains covers $3160 \mathrm{ha}$; it is valued for the large number of plant and animal species and interesting ecotypes it contains. 
The main land-use types are evergreen montane cloud forests and grasslands. Part of the grassland was cultivated in the 1960s and is now under fallow. The major soil type is redyellow podzolic. Peat accumulation can be seen. The average annual rainfall is about 2150 Inm.

\section{Method}

Infiltration and hydraulic conductivity tests were made in the field, in three plots in each land-use type: forest, natural grassland, and formerly cultivated grassland. Soil samples were brought to the laboratory for the determination of soil texture, organic matter and bulk density.

A hand driven soil auger was used to collect the soil samples at two sites in each land-use type. They were collected from 12.5 down to $337.5 \mathrm{~cm}$ at $25 \mathrm{~cm}$ intervals. A pipette method was used to determine the proportions of sand, silt and clay (Gee \& Bauder, 1986). The USDA classification was used to determine the texture. The Munsell soil colour chart was used to determine the colour in the field at the time of sampling. The colour of the air-dried samples was also determined.

Organic matter analysis was done on the same samples. Since there were no visible indications of the presence of organic matter below $1 \mathrm{~m}$, analyses were carried out only for samples down to that depth. They were done at the soil science laboratory of the Faculty of Agriculture using a colorimetric method.

For the estimation of bulk density, a pit was dug in the formerly cultivated grassland, about $2.5 \mathrm{~m}$ deep. A core sampler was driven horizontally into the sides of the pit to collect undisturbed samples at $0.5 \mathrm{~m}$ intervals from the surface to $2.5 \mathrm{~m}$ depth. Two core samples were taken at each depth. In the forest and natural grassland the pits we 


\section{Results and discussion}

\section{Texture and colour}

The texture of the soil profiles of the three land-use types is shown in Figure 1. In general, the top layers have more sand, which decreases with the depth, while the clay fraction increases.

Although there were considerable variations, the surface layers are sandy loam, while the deeper layers are sandy clay loam. The colour is dark brown down to about $0.75 \mathrm{~m}$, while deeper layers are yellowish to pink.

\section{Organic matter}

Figure 2 shows organic matter content. In general, it is greater in the grassland than in the forest soils. Grassland soils have more than $20 \%$ organic matter in the top $0.25 \mathrm{~m}$ while forest has only about $13 \%$. The content in the $0.25-0.50 \mathrm{~m}$ layer is twice as great in the grasslands than in the forest. However, below $0.5 \mathrm{~m}$ there was hardly any difference in the organic matter content between land uses. The greater depth of soil containing organic matter, in grassland as compared with forest, can be scen throughout the Horton Plains reserve. This high organic matter content is presumable due to the low temperatures and slow rates of decomposition, and that in cold climates it is common for grassland organic matter to accumilate in more than that derived from forest litter. 


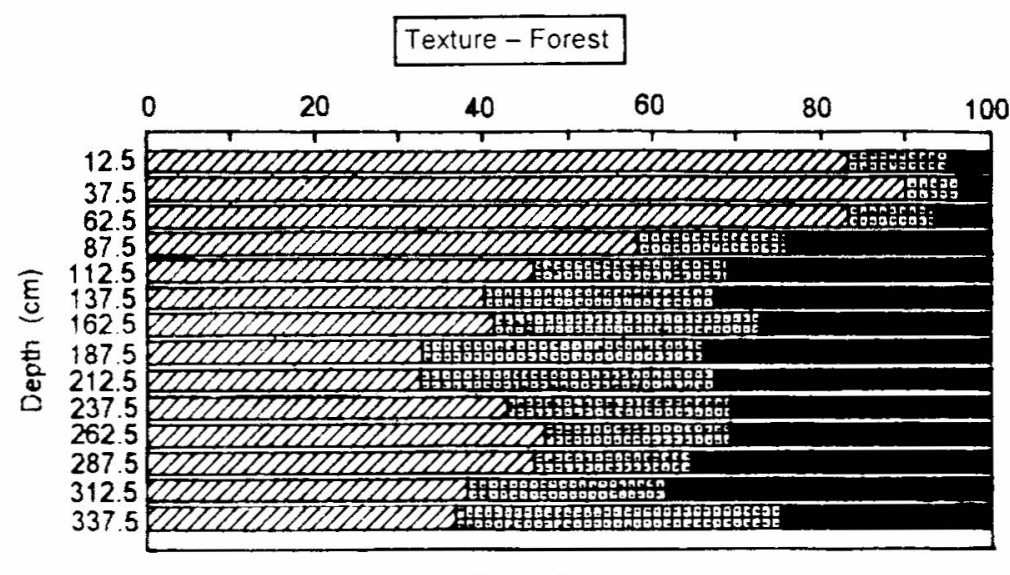

Percentage

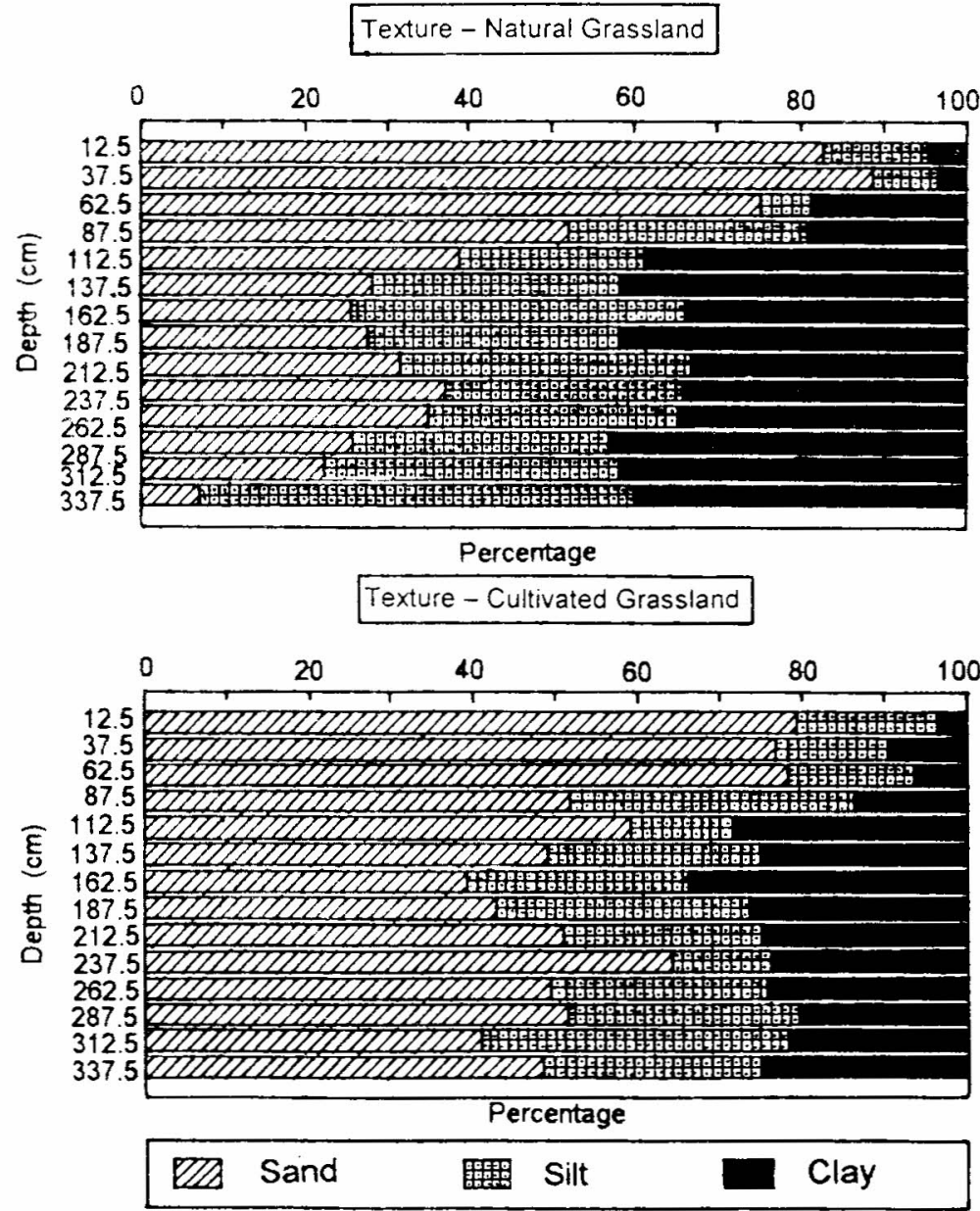

Figure 1: Texture of soil profile at Horton Plains 


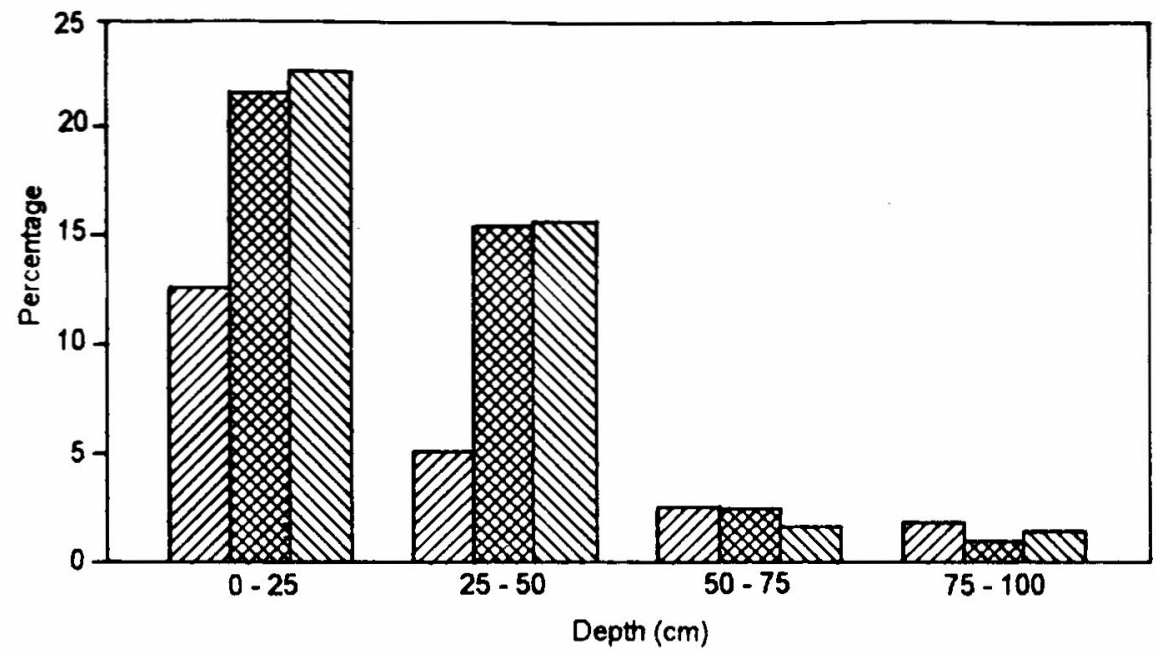

Ea Forest Natural Grassland Cultivated Grassland

Figure 2: Organic matter content in different layers of Forest, Natural grassland and Cultivated grassland in Horton plains

\section{Bulk density}

Figure 3 shows the bulk density at different soil depths for the three different land-use types. The values are very low in the top $0.25 \mathrm{~m}$. Below $0.25 \mathrm{~m}$ they increase to more than 1 . except in the formerly cultivated grassland. Below $0.5 \mathrm{~m}$ the differences between the three land uses are minimal. These observations can be very easily explained by reference to the corresponding organic matter values; as is to be expected, soil layers with high organic matter content tend to have lower bulk density.

\section{Hydraulic conductivity}

Table 1 gives the average hydraulic conductivity of the different land-use types, as measured in situ. These values vary between individual sites more than between land-use types. Overall. they range from 2 to $8 \mathrm{~mm} / \mathrm{hr}$.

\section{Table 1 : Hydraulic conductivity $(\mathrm{mm} / \mathrm{hr}$ )}

\begin{tabular}{lllll}
\hline & Site 1 & Site 2 & Site 3 & Average \\
Forest & 5.7 & 3.0 & 4.4 & 4.4 \\
Natural grassland & 5.1 & 0.5 & 1.1 & 2.2 \\
Formerly cultivated grassland & 1.5 & 8.1 & 12.1 & 7.2 \\
\hline
\end{tabular}




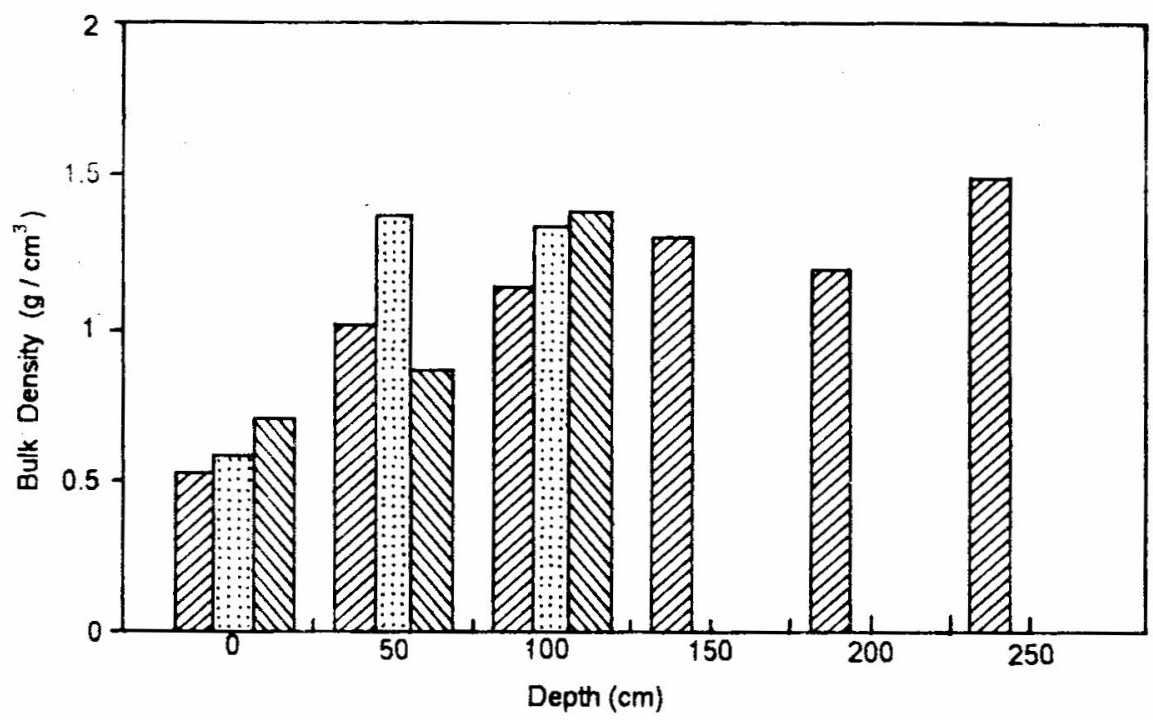

Worest Natural Grass Cultivated Grass

Figure 3: Soil bulk density values of Horton Plains $\left(\mathrm{g} / \mathrm{cm}^{3}\right)$

\section{Infiltration}

As the experiments were carried out during a relatively dry period in April, the initial rates for all three sites were high. However, they diminished rapidly after about 10 minutes. The infiltration capacity varies considerably between sites within the same land use, eg in the forest the initial rates at the three sites were 750,148 , and $1818 \mathrm{~mm} /$ hour at sites 1,2 , and 3 . On average. the forest has the highest rate, followed by natural grassland, and the formerly cultivated grassland has the lowest.

A representative infiltration curve was derived for each land-use type from the observed infiltration rates. First, for each test made, values were found for the constants $a$ and $b$ in the infiltration equation:

$$
\mathrm{I}=\mathrm{a} \mathrm{T}
$$

where $I$ is the infiltration and $T$ is the elapsed time. 
The values of $a$ and $b$ for each of the three sites under one land use were added and divided by 3 to get arithmetic mean values, which were then used to derive the infiltration rate curves shown in Figure 4.

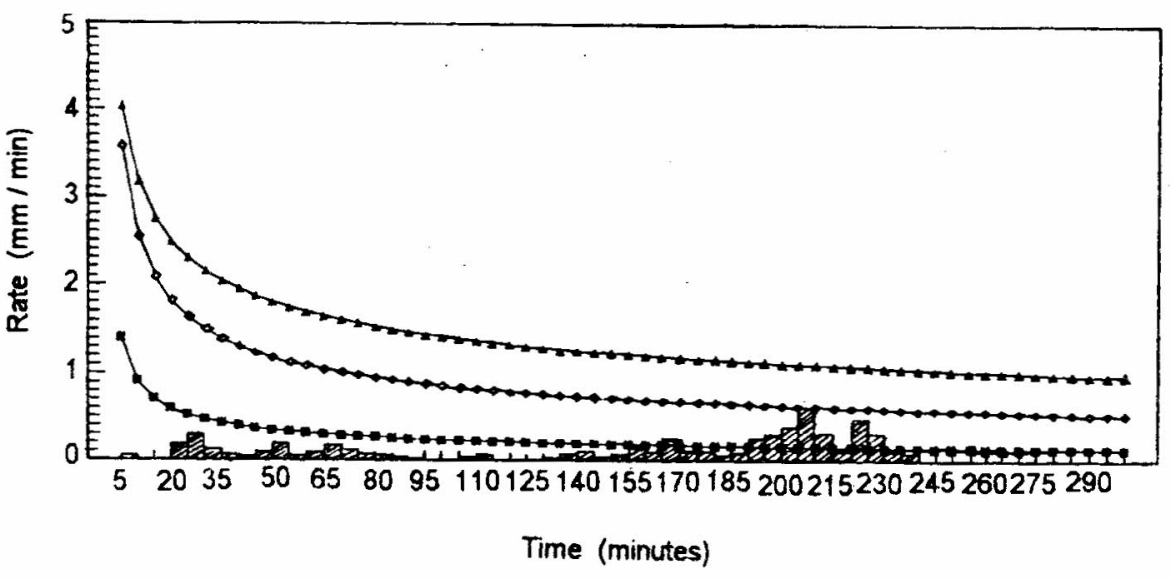

$$
\text { - Cultivated Grassland \& Natural Grassland + Forest Rainfall }
$$

Figure 4: Infiltration rates in different landuses and rainfall

\section{Runoff generation}

The five-minute rainfall from the heaviest rainfall event observed during the period of study from January to June 1996 (31.7 mm on 14 June) was used for the comparison. The rainfall values, divided by 5 to get the per minute rate, are shown in Figure 4. Runoff would be generated when the rainfall histogram goes above the infiltration curve. According to the graph, there would not have been any surface runoff from forest or natural grassland; all the rain falling on these two land-use types should have infiltrated. The total area of the rainfall histogram represents the total rainfall, while the histogram height at each minute represents the rainfall intensity. From the cultivated grassland, about $26 \%$ of the rainfall would have generated surface nunoff. 
It appears then that most of the rainfall goes directly into the soil as infiltration. The lower bulk density in the upper layers, due to the high organic matter content and the sandy loam soil, is responsible for high infiltration rates. However, below the surface layers the hydraulic conductivity values are relatively low. Therefore, it is likely that water which enters vertically into the soil profile will move laterally, above the layers with low hydraulic conductivity. This process is known as the "thatched roof analogy" of water movement through the soil profile (Ward and Robinson, 1990).

\section{Conclusions}

The following conclusions can be drawn:

- High infiltration rates under forest, natural grassland and formerly cultivated grassland are due to the higher organic matter (which gives low bulk density) and to the sandy loam soil in the surface layers.

- Since infiltration values are high compared with the low rainfall intensities cxperienced, most of the rain enters the soil. Most probably, much of the water then moves laterally within the upper part of the soil profile.

- Land use has a very marginal effect on nunof generation at Horton Plains. Soil and climate are the predominant factors.

\section{Reconmendations}

Further measurements should be made of the hydraulic conductivity of different soil layers. More infiltration studies are also recommended, in view of the large variation within land uses. Runoff plot studies should also be carricd out during rainy periods in order to find out how much s? rface numoff there really is.

\section{References}

Gec, G.W. and Bauder, J.IV. (1986). P'article size analysis. In A. Klutc (Ed.) Methods of soil analysis, 2nd edition, Part 1, pp.394-409. American Society of Agronomy/Soil Science Society of America.

Glemn, O.S, Richard, K.F, Talcolt, W.E and Barns, K.K. (1981). Soil and water conservation engineering, 3rd edition. New York, John Wiley and Sons. 